METODOLÓGICOS E

NOVOS CENÁRIOS PARA

FUNDAMENTOS, ASPECTOS

\author{
SUSTENTABILIDADE

PARA

t

s.

(3) 


\section{SOBRE OS AUTORES}

Debora Barauna | debora.barauna1@gmail.com

Lattes: http://lattes.cnpq.br/6098263490478903

Designer e Pesquisadora, vinculado à linha de pesquisa de Sistemas de Produção e Utilização, com atuação na interface de PD\&I por meio do Design, relacionando a aprendizagem e concepção sustentável entre materiais, tecnologias e produtos. Graduada em Design (UNIVILLE, 2004), Mestre em Saúde e Meio Ambiente (UNIVILLE, 2009) e Bolsista de Doutorado da CAPES (2014 a 2018) pelo Programa de Pós-Graduação em Design (PPGDesign) da UFPR.

Dalton Luiz Razera | daltonrazera@ufpr.br

Lattes: http://lattes.cnpq.br/3905439141331112

Professor Titular do PPGDesign e da Graduação de Design da UFPR, vinculado à linha de pesquisa de Sistemas de Produção e Utilização com pesquisas em produtos sustentáveis a base de matéria prima de origem florestal. Graduado em Design (UFPR, 1978); Licenciatura em Ensino (CEFET/PR, 1985); Especialização em Industrial Design (JICA/Japão, 1989); Mestre em Engenharia de Produção (UFSC, 2004); Doutor em Engenharia Florestal (UFPR, 2006). 


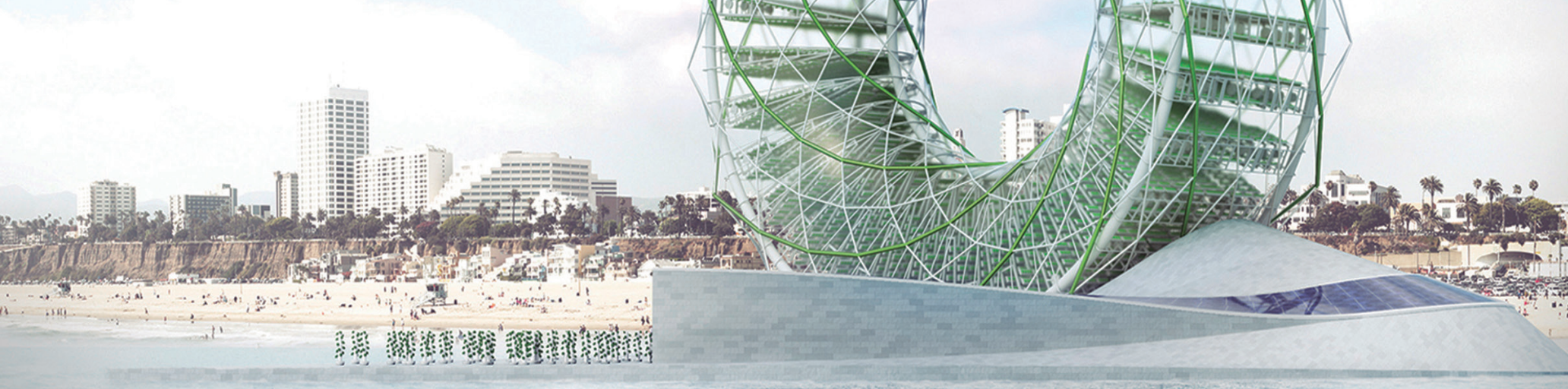

\title{
Sustentabilidade, desenvolvimento e Inovação no século 21: demandas para o design de materiais avançados
}

\author{
Sustainability, development and Innovation in the \\ 215t Century: demands for the Advanced Materials \\ Design
}

Debora Barauna, Dalton Luiz Razera

\section{Resumo}

A sustentabilidade, o desenvolvimento e a inovação são questões contemporâneas em um cenário que se configura para o desenho de um novo mundo material. Desde a virada do milênio, muitas direções para o desenvolvimento da sociedade no século 21 foram propostas na literatura entre os materiais e o design para a promoção da inovação. A compreensão dessas direções é discutida neste estudo por meio de uma revisão narrativa da literatura. As técnicas de pesquisa bibliográfica e análise de conteúdo foram empregadas para o mapeamento de trabalhos publicados (2001-2015). Os resultados encontrados mostraram que há uma convergência de ações para o design de materiais avançados nos setores de pesquisa, desenvolvimento e inovação. A sustentabilidade é priorizada diante do uso dos recursos materiais na ciência, na tecnologia e no design. A exigência é por projetos de inovação que promovam efetiva transformação social e maior colaboração e criatividade nos processos.

Palavras-chave: Design; Materiais avançados; Inovação; Tendências; Sustentabilidade

\begin{abstract}
The sustainability, development and innovation are contemporary issues in a scenario that sets out for the designing of a new material world. Since the turn of the millennium, many directions for the development of the society in the 21st Century have been proposed in the literature between materials and design for the promotion of innovation. The understanding of those directions is discussed in this study through a literature narrative review. The bibliographical research and content analysis were techniques used for the mapping of published works (2001-2015). The results show that there is a convergence of actions for the advanced materials design in the research, development and innovation sectors. The sustainability is prioritized on the use of the material resources in the science, technology and design. The demand is for innovation projects that promote effective social transformation and greater collaboration and creativity in the processes.
\end{abstract}




\section{INTRODUÇÃO}

A Sociedade Contemporânea baseia-se no uso de materiais para quase tudo que produz e consome. 0 homem desde a sua existência sempre fez uso dos recursos naturais para a sua sobrevivência. No entanto, com o avanço das civilizações, o desenvolvimento econômico e tecnológico transformou o consumo dos recursos naturais em recursos materiais, ou seja, em matérias primas e insumos para a produção e o consumo.

No design os recursos materiais são utilizados para dar vazão às ideias, que decorrem da união entre valores tangíveis e intangiveis dos materiais, tais como propriedades e características técnicas, funcionais, simbólicas, emocionais entre outras. 0 objetivo é o uso do material em um produto orientado por demandas ou necessidades do usuário. Porém, em um universo de aumento de complexidade e de niveis de insustentabilidade do planeta, com a escassez das fontes de fornecimento material, é preciso reavaliar as demandas para replanejar o uso dos recursos materiais por novos sistemas e processos que resultem em soluções sustentáveis para a sociedade.

A ideia de soluções sustentáveis é traduzida na proposta conceitual Ring Garden de Alexandru Predonu (Romênia) submetida ao Land Art Generator - LAGI 2016, um concurso bienal de design sustentável. O projeto usa tecnologia de coleta de água por dessalinização osmótica com energia solar por painéis fotovoltaicos e biorreator de algas para produzir 60 milhões de litros de água potável usados, em parte (cerca de $35 \%$ ), no cultivo aeropônico de 18 mil quilogramas de plantas (LAGI, 2016).

O planejamento de sistemas e processos para a obtenção de soluções sustentáveis para a sociedade exige pensar em inovação no sentindo de mudança ou transformação social, também chamada de inovação disruptiva. Esta é uma estratégica conexa à pesquisa e ao desenvolvimento (P\&D), tratada neste estudo como pesquisa, desenvolvimento e inovação (PD\&l).

Na concepção de um processo de PD\&I a ideia é suscitar uma interdependência entre as atividades de pesquisa, desenvolvimento 
e inovação e seus objetos de estudo, tais como materiais, tecnologias e produtos. Um processo integrado e colaborativo. As ações são iniciadas pelo planejamento dos extremos do processo, a entrada (problema) e saída (solução). Segue-se o conceito dos modelos FrontEnd, onde primeiro identifica-se oportunidades de geração de valor e depois desenvolve-se o projeto (Roadmap). Na entrada do processo propõe-se haver a identificação de reais demandas da sociedade, essas caracterizadas muitas vezes como problemas complexos (wicked problems). Já na saída do processo é necessário que se obtenha a proposta de uma solução sustentável, potencialmente, inovadora para a sociedade (Figura 1).

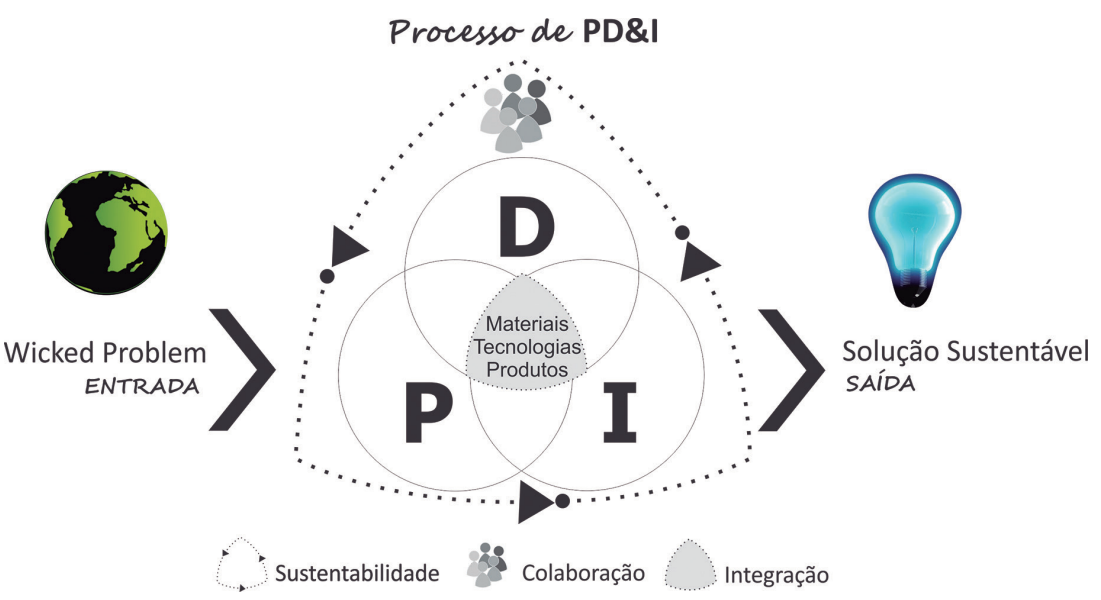

Figura 1: Concepção de um processo de PD\&I para a obtenção de soluções sustentáveis. Fonte: Elaborado pelos autores.

A concepção proposta enfatiza interações complexas inerentes à Sociedade Contemporânea. Na estratégia PD\&I são necessárias ações de práxis (consciência), além de práticas, para buscar maior equilíbrio entre as dimensões da sustentabilidade, com a conscientização, como cita McBride (2011), dos limites entre o raro e real. São relações complexas que demandam considerar os impactos sociais, ambientais e econômicos tanto do ponto de vista das escolhas de materiais, tecnologias e produtos (quem consome) como das ofertas (quem fornece e produz). "Para estabelecer essas relações, o indivíduo precisa interagir, trocar e integrar informações e conhecimentos, ou seja, precisa se comunicar" (CAMATTI, 2010, p. 4). 
Sobretudo, na realidade brasileira a relação da ciência e tecnologia (C\&T) dos materiais com demais áreas do conhecimento, interessadas no processo de promoção da inovação, como o design, ainda são incipientes. Isto, tanto no aspecto mecânico de integração de processos (etapas, métodos, ferramentas e atividades) como no sentido humano de interação ou comunicação entre as partes interessadas (stakeholders). Porém, no cenário mundial o processo de design vem sendo relacionado à concepção de novos materiais ou materiais avançados para a promoção da inovação e dirigido por diversas tendências de PD\&I para o desenvolvimento da sociedade no século 21.

Dentro deste contexto, o presente estudo visou compreender as direções em PD\&I para o desenvolvimento da sociedade no século 21 em relação à interface da C\&T dos materiais e do design. Por meio de uma revisão narrativa da literatura, a proposta foi discutida diante de várias questões contemporâneas da sociedade, tais como: ambientais, políticas, econômicas e culturais. A técnica de pesquisa bibliográfica foi utilizada para mapear trabalhos publicadas entre o período de 2001 a 2015 e a análise de conteúdo do tipo temática foi empregada para a seleção e interpretação das informações encontradas.

A seguir o estudo foi estruturado de modo a expor primeiro a fundamentação do método de pesquisa aplicado e na sequência os resultados obtidos foram apresentados em duas seções. Na primeira seção a sustentabilidade é ressaltada como uma força motora para os avanços da sociedade, pressionando os setores de desenvolvimento a repensarem suas tecnologias, mediante às estimativas de escassez das fontes de recursos materiais, por exemplo. Já a seção seguinte enfatiza as direções em PD\&I no século 21 entre os materiais avançados, as altas tecnologias e o design. Diversas tendências para a concepção de soluções sustentáveis são indicadas, destacando-se os nanomaterias, os materiais verdes, os materiais inteligentes e a biomimética. Por fim, remete-se a ideia do desenho de um novo mundo material, como ditou Oslon (2001), com o design de materiais avançados. Um novo pensamento material é proposto com a consideração dos contextos e significados dos materiais ao produto. Ainda é observada a demanda por maior colaboração e criatividade na interface entre os materiais e o design bem como pela gestão emergente, de projetos de PD\&I. 


\section{MÉTODO DE PESQUISA}

Foi realizado uma revisão narrativa da literatura "para descrever e discutir o desenvolvimento [...] sob ponto de vista teórico ou contextual" (ROTHER, 2007, p. V). Um estudo de revisão narrativa da literatura caracteriza-se por uma pesquisa de mapeamento, onde, inicialmente, é realizado um levantamento bibliográfico amplo e aberto de trabalhos publicados com o uso de termos abrangentes de busca (VOSGERAU e ROMANOWSKI, 2014). Neste estudo os principais termos de busca empregados foram 'novos materiais', 'materiais avançados' ou 'advanced materials', 'material innovation'e 'innovative materials'. Ambos relacionados ao design por meio do operador booleano AND ou outro, conforme o guia do sistema de busca utilizado, tais como o Google Acadêmico e Portal de Periódicos da CAPES. Deste modo, o estudo tratou-se de uma pesquisa qualitativa e bibliográfica, onde foram coletados dados em livros, artigos de periódicos eletrônicos e de congressos entre outros, publicados no período de 2001 a 2015.

A análise de conteúdo do tipo "temática" foi empregada para a seleção e interpretação das informações obtidas. Tal tipo de análise "trabalha com a noção de tema, o qual está ligado a uma afirmação a respeito de determinado assunto; comporta um feixe de relações e pode ser graficamente representada por meio de uma palavra, frase ou resumo" (GERHARDT e SILVEIRA, 2009, p. 84). Com a análise de conteúdo foi elaborado um ensaio teórico a fim de sintetizar e contextualizar o tema proposto, promovendo a discussão por meio da relação entre as produções anteriores identificadas e apontando perspectivas de "caminhos ou referências teóricas para novas pesquisas" (VOSGERAU e ROMANOWSKI, 2014, p. 174).

\section{SUSTENTABILIDADE E DESENVOLVIMENTO}

A sustentabilidade na contemporaneidade é destacada como uma potencial condutora de avanços na C\&T dos materiais. Essa transforma a maneira como é pensado os processos de P\&D em materiais bem como questiona o modo como as tecnologias e os produtos são produzidos e consumidos. 
PREVISÕES DE CRESCIMENTO DA POPULAÇÃO MUNDIAL EM BILHÕES DE PESSOAS

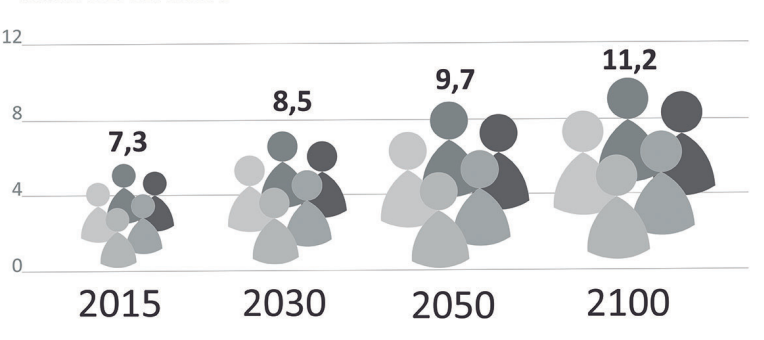

A
Sabe-se que toda atividade humana exerce impactos negativos sobre o meio ambiente, que tem capacidade limitada para absorver todos esses impactos sem danos irreversíveis (FIELD, CLARK e ASHBY, 2001). Só entre 1960 a 2010, em relação a todo o período anterior de existência da humanidade, a utilização dos recursos materiais foi aumentado $1.000 \%$ (McBRIDE, 2011). O que tem ocasionado ao planeta diversos problemas ambientais, como a escassez dos recursos naturais. Ao avançar dos anos, na medida que se relaciona dados de previsão do crescimento populacional e da pegada ecológica global, os resultados são ainda mais alarmantes (Figura 2). Segundo dados da United Nations (2015) a população mundial pode aumentar 32\% até 2050 e 53\% até 2100, Já a Global Footprint Network (2017) alerta que serão necessários dois planetas Terra em 2030 para suportar os modos de consumo atual da humanidade.

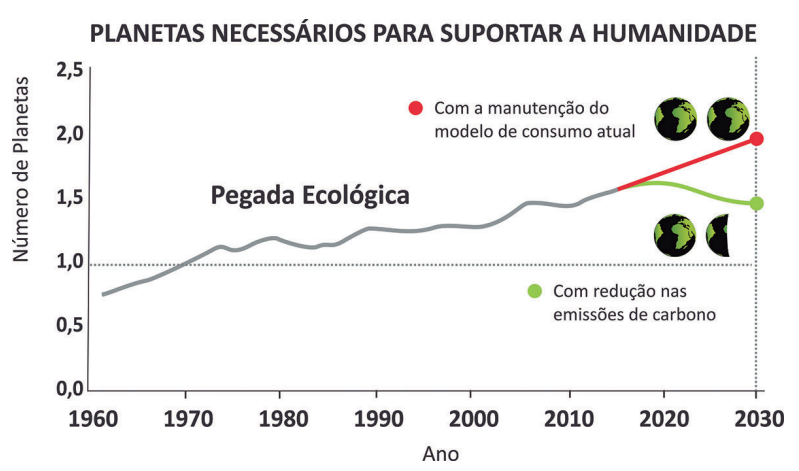

B

Figura 2: (A) Previsões de crescimento da população mundial e (B) pegada ecológica global. Fonte: (A) Dados do United Nations (2015) e (B) adaptado de Global Footprint Network (2017).

Com isso, muitos fabricantes de materiais e produtos no mundo tem desenvolvido novas tecnologias ou revisado as suas já existentes com o intuito de adaptarem-se às pressões ambientais existentes (BELL, 2011). A ideia é que desenvolvedores de materiais e produtos assumam papel mais crítico e criativo sobre como otimizar os recursos materiais bem como sobre como questionar o uso de resíduos e o pós-uso dos materiais e produtos considerando o seu retorno ao ciclo produtivo. "Em muitos casos, os produtos são desviados do fluxo de resíduos e convertidos em usos que apresentem maior valor quanto às suas aplicações originais" (BELL, 2011, p. 6). 
No design as formas mais óbvias para preservar os recursos materiais são pela criação de produtos menores, mais duráveis e passíveis de reciclagem no fim da sua vida útil. "Porém, a obviedade aparente as vezes pode ser enganosa. Materiais e formas de energia partem de um complexo sistema interativo" (FIELD, CLARK e ASHBY, 2001, p. 720). "A demanda, a produção e o preço dos materiais estão estreitamente relacionados com o consumo de energia. 0 consumo de energia na produção de materiais é da ordem de 15 a $25 \%$ de toda a energia primária utilizada nas economias industrializadas" (PADILHA, 2000, p. 26). Field, Clark e Ashby (2001) trazem à tona essa complexidade em um diagrama de relações do consumo de material e energia com linhas de conexão que indicam influências de ações e consequências tanto positivas como negativas ao processo. Respectivamente, essas influências são representadas no diagrama por sinais de mais [+] ou [-]. Já um par de sinais de mais e menos [+|-] sugere que o condutor tem capacidade de gerar ambas influências, positiva e negativa, ao processo (Figura 3).

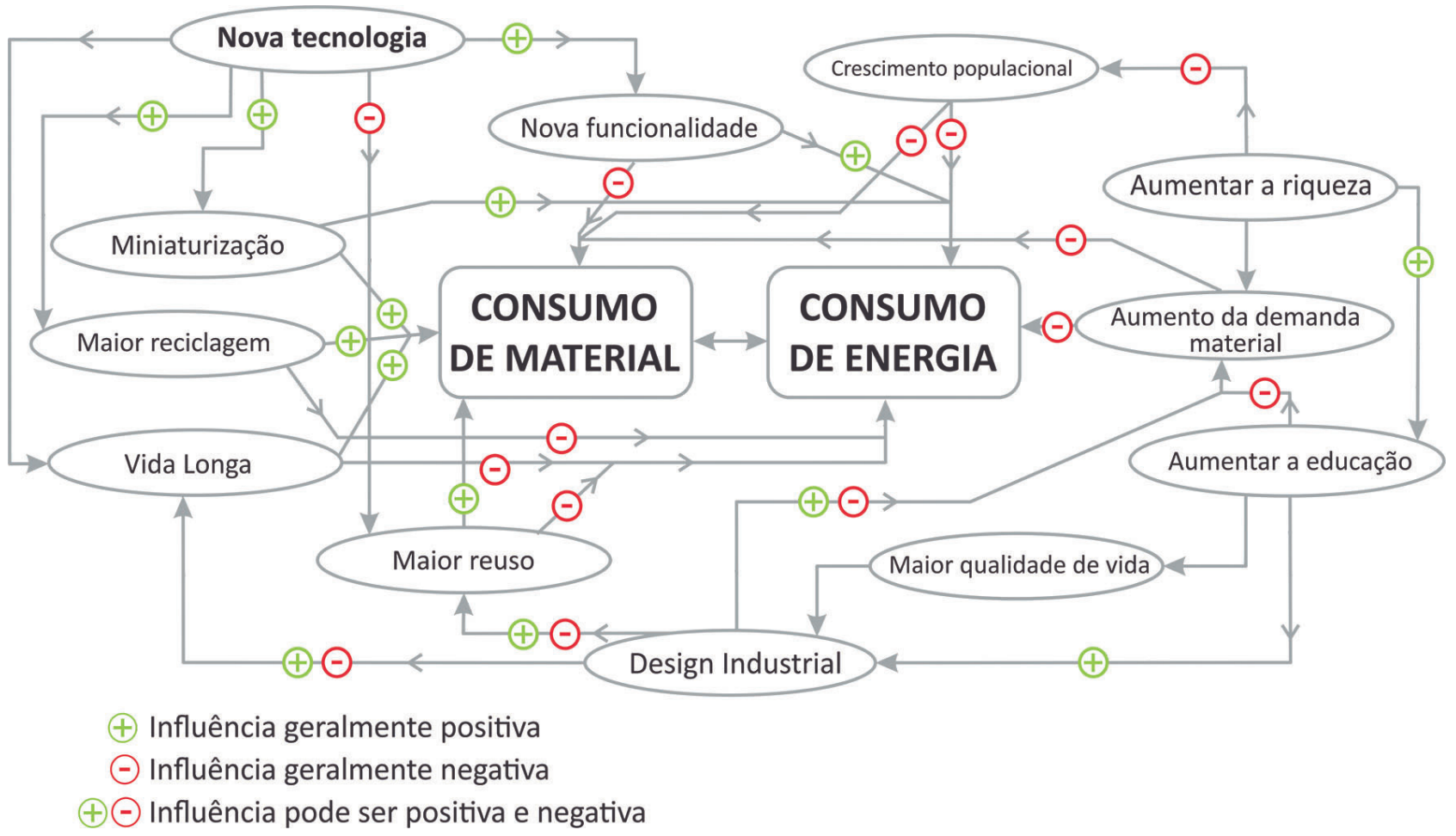

Figura 3: Influências no consumo de materiais e energia. Fonte: Adaptado de Field, Clark e Ashby (2001). 
Agora observem as linhas de influência das novas tecnologias e suas consequências como exemplo: 0 aumento da população com maior poder aquisitivo e grau de instrução possibilitou maior acesso aos produtos [+|-], por conseguinte, acelerou o desenvolvimento de novas tecnologias [+]. Estas questões somadas às tendências dos sistemas de informação, da comunicação, do design e do comportamento humano, onde estar incluído na Sociedade Contemporânea significa, em parte, possuir a última tecnologia e design do momento, gerou o modismo e dinamizou o uso e descarte dos produtos [-]. Em suma, para os autores do diagrama novas tecnologias em forma de produtos catalisam o consumo e deliberaram sobre a obsolescência desses. Os autores destacam que " $80 \%$ dos produtos eletrônicos são descartados enquanto ainda funcionam" (FIELD, CLARK e ASHBY, 2001, p. 720). Assim, mesmo que esses produtos tenham sido projetados com materiais e formas de energia a influir positivamente na sua vida longa, é a simples decisão de consumo do usuário que determina o tempo de vida útil dos produtos. 0 celular é o artefato mais expressivo para ilustrar esta questão. Por outro lado, vive-se em uma era em que novas tecnologias oferecem modos de energia mais limpo. Portanto, muitas vezes, estender a vida útil de produtos antigos, desenvolvidos com modos de energia menos eficientes, gera-se uma influência negativa ao processo (FIELD, CLARK e ASHBY, 2001).

Em contraponto, as tecnologias de energia limpa, como turbinas eólicas, energia para veículos elétricos e células solares de película fina utilizam materiais com propriedades magnéticas, catalíticas e luminescentes que são classificados como críticos por possuírem alta demanda e substitutos limitados (ENERGY, 2016). A exemplo disto é citado os ímãs de neodímio empregados em turbinas eólicas e veículos elétricos, além de outros materiais críticos como európio, térbio e ítrio utilizados em lâmpadas fluorescentes, televisores de tela plana e telas de computadores. Assim, de acordo com a fonte Energy (2016, p. 2) a "disponibilidade básica não é o único fator que afeta o risco global de fornecimento de um material crítico", demais fatores são: demandas tecnológicas concorrentes (como computadores, telefones, celulares etc.); falta de diversidade de produtores e regulamentação de países considerados grandes produtores de matérias primas essenciais. 
Políticas de uso de materiais críticos já é uma realidade em vários países da Europa e no Estados Unidos. Em 2014, um Relatório da Comissão Europeia divulgou uma lista de 20 matérias primas com perspectivas de fornecimento crítico no mundo (Figura 4). Foram considerados riscos de escassez do material e a sua repercussão na economia.

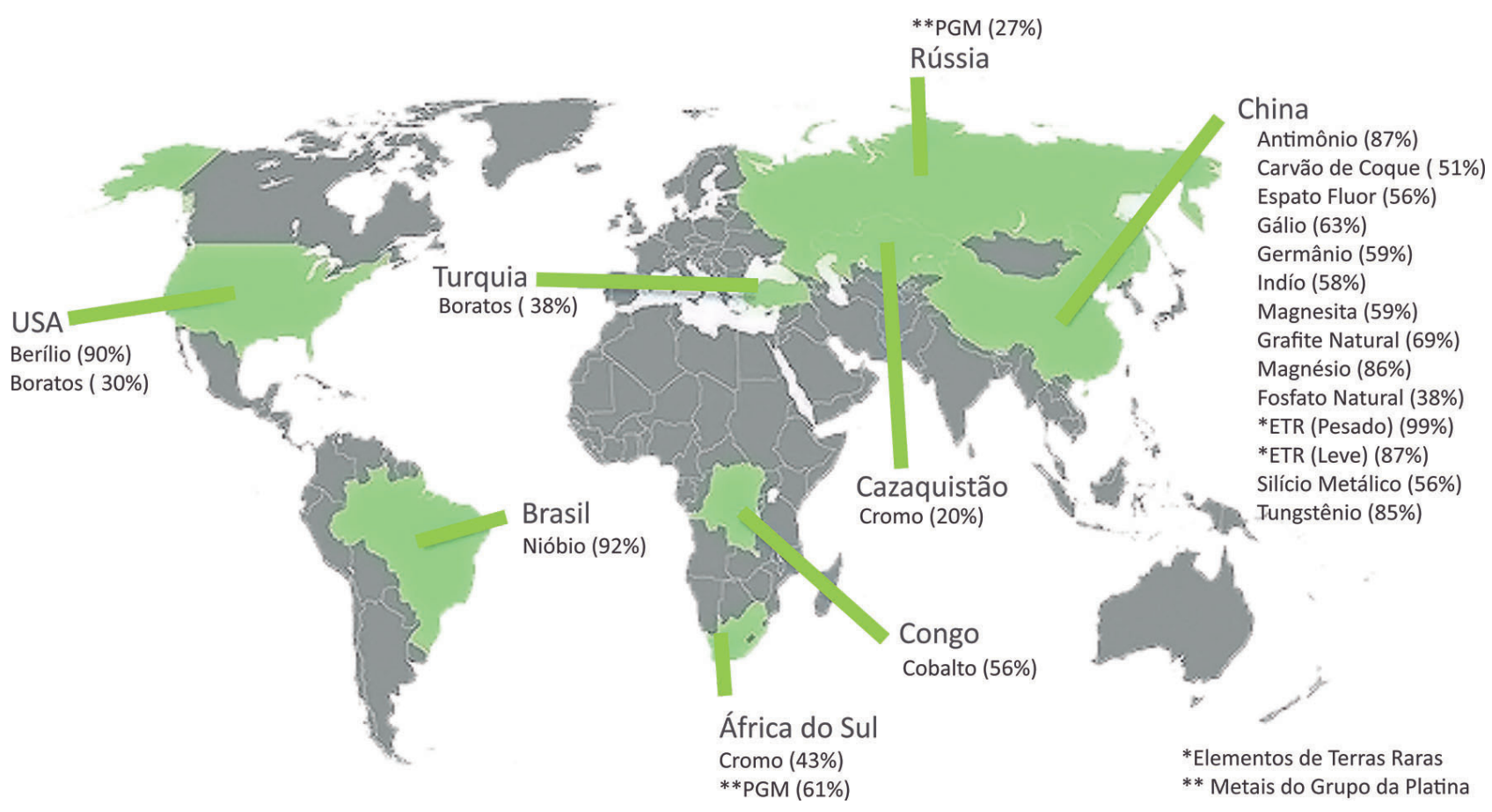

Figura 4: Distribuição dos materiais críticos no mundo. Fonte: European Commission (2014).

A China revela-se como o país mais influente quanto à oferta mundial dessas matérias primas essenciais, tendo o domínio de 15 dentre todas aquelas relacionadas. Vários outros países têm uma posição dominante no fornecimento de matérias primas específicas, como é o caso do Brasil com o nióbio, além dos EUA, da Rússia, da África do Sul, da Turquia, do Cazaquistão e do Congo.

A reciclagem, reutilização e utilização mais eficiente dos materiais críticos poderiam contribuir para a redução do consumo de energia e da demanda de extração mundial (ENERGY, 2016). Entretanto, apenas $1 \%$ dos materiais críticos são reciclados no fim da vida útil de um produto (EUROPEAN COMMISSION, 2014). 
Com este panorama, projetos de usos de materiais críticos devem tornar-se cada vez mais estratégicos nas esferas políticas, econômicas, ambientais, sociais e culturais, tanto em instância local como global (McBRIDE, 2011). De modo geral, Dobrzanski (2006) considera que a situação e as previsões atuais ao fornecimento e uso de recursos materiais, críticos ou não, exigem, cada vez mais, a coordenação de atividades estratégicas voltadas para a preservação das matérias primas disponíveis, consistindo em:

a) Projetar para o uso econômico dos materiais, principalmente, daqueles raros e com indícios de esgotamento, considerando o consumo mínimo de energia.

b) Usar materiais com maior disponibilidade de acesso e aproximação territorial da aplicação fim, considerando ainda a grande margem de sobrevida desses, bem como o menor consumo de energia.

c) Promover pleno usa da reciclagem para a reutilização e valorização dos materiais, quando houver garantia de redução do consumo de energia e insumos, além de se mostrar economicamente viável.

Neste contexto, Margarethe Hofmann-Amtenbrink no Simpósio Internacional de Materiais, MATERIAIS 2015 (2015), realizado na Universidade do Porto em Portugal, dissertou sobre materiais críticos em produtos inteligentes como oportunidade e desafios para a C\&T dos materiais, engenharia e design. Em sua visão, a inovação em materiais leva um longo tempo desde a ideia até a comercialização em produtos. Desta forma, sugere que para evitar estratégias erradas de longo prazo de PD\&I é necessário hoje e para o futuro considerar a pesquisa das reservas e da disponibilidade dos elementos críticos em materiais, como a mineração e o processamento, bem como o uso e o seu potencial de reciclagem.

Enfim, atrelar a sustentabilidade ao desenvolvimento continua a ser um desafio para a Sociedade Contemporânea. Todavia, direções em PD\&I no século 21 buscam aproximar o design aos materiais avançados, a fim de obter maior previsibilidade de soluções que ofereçam maior qualidade ambiental e melhores condições de vida para a sociedade. Algumas dessas direções, citadas na literatura entre 2001 e 2015, são apresentadas na sequência deste estudo. 


\title{
4 DIREÇÕES EM PD\&I NO SÉCULO 21
}

\author{
"Nada é estático" (FIELD, CLARK e ASHBY, 2001, p. 724). Materiais
} são melhorados para atender as necessidades de hoje, mas, antes de as melhorias estarem completas, as condições limites são alteradas, exigindo novos desenvolvimentos (FIELD, CLARK e ASHBY, 2001). 0 período de obsolescência curto do conhecimento na C\&T dos materiais tem exigido, cada vez mais, estudos complexos e dinâmico em PD\&l para aumentar o nível de conhecimento e acelerar a transferência de tecnologias para a sociedade (DOBRZANSKI, 2006). Para Fuck e Vilha (2011, p. 14) "o fato é que estamos diante de uma maior complexidade dos problemas científicos, tecnológicos e inovativos na atualidade".

Com a contemporaneidade surgiu um "mundo novo e infinito dos materiais que selecionamos, escolhemos e combinamos para produzir outros, de cada vez mais alto desempenho" (KULA e TERNAUX, 2012, p. 315). No século 21 os novos materiais também foram chamados de materiais avançados, aqueles que são manipulados e controlados para que propriedades funcionais e desejadas possam ser criadas (PADILHA, 2000; BELL, 2011; DOBRZANSKI, 2006). Os materiais avançados são obtidos por meio de "processos de síntese da matéria-prima, com controle das características estruturais do material" (CGEE, 2010, p. 7), visando desempenho sistêmico e específico do produto acabado, o que é chamado também de design de materiais. Esses "viabilizam engenhos e soluções de grande potencial estratégico" (CGEE, 2010, p. 7), conduzindo a introdução radical de tecnologias e produtos (BELL, 2011).

Na literatura técnica-científica destacam-se diversas tendências relacionadas aos materiais avançados e ao design, indicando direções de desenvolvimento da sociedade no século 21. Algumas dessas tendências são apresentadas na sequência de modo cronológico entre os anos de 2001 e 2015.

As direções de desenvolvimento do mundo no início do século 21 diferemse, expressivamente, daquelas do final do século 20. 0 panorama deixado pelo último século foi de um domínio dos materiais estruturais e do tamanho mínimo ou reduzido dos produtos. Também, gerou-se 

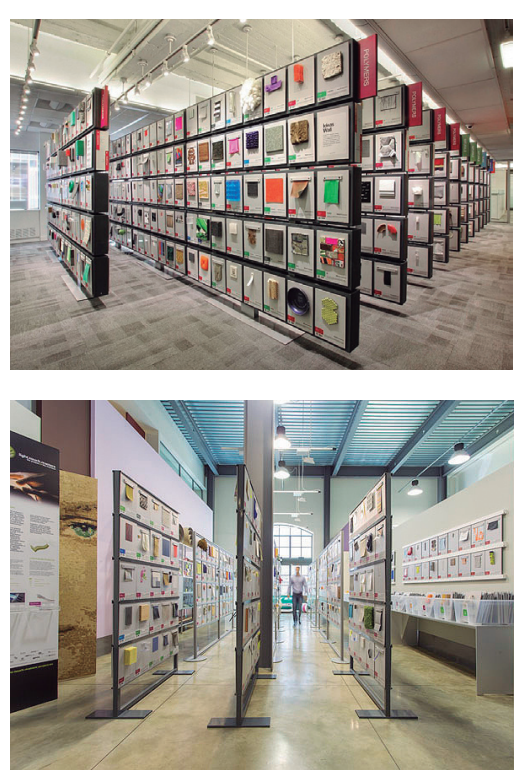

Figura 5: Material ConneXion em Nova York e Milão. Fonte: Material ConneXion (2017a). maior funcionalidade para os produtos e as prioridades foram noções de defesa, energia nuclear e espacial. Já no século 21 as questões voltam-se para o crescimento econômico, a gestão do conhecimento e a saúde. Com uma indústria globalizada e um livre comércio virtual os atributos econômicos de materiais, a propriedade intelectual e as estratégias de negócios são enfatizados. A ênfase também recai sobre novos estudos de materiais e tecnologias relacionados aos atributos não estruturais de materiais elétricos, ópticos, magnéticos e biológicos. São propriedades de filmes finos, de superfícies ou de interfaces. Nas superfícies destacam-se também os atributos percebidos como cor, textura, sentir, além das associações que os materiais adquirem. Estágios de maturidade dos produtos e previsibilidade de novos cenários relançam o design, seus conhecimentos e sua capacidade criativa individual e coletiva ao encontro de conceitos e atributos associativos, percebidos, estéticos e emocionais para materiais e produtos (FIELD, CLARK e ASHBY, 2001).

Foi com esse cenário que George M. Beylerian fundou em 1997 a Material ConneXion, uma das primeiras plataformas de materiais a promover uma interface com o design (Figura 5).

Ainda, segundo Field, Clark e Ashby (2001) as preocupações ambientais ganham atenção como atributos de projeto, onde demanda, fornecimento de recursos materiais e impacto ambiental são itens considerados. São exigidas soluções de análise de sistemas; uso de recursos materiais renováveis; prática de reciclagem e extensão da vida útil dos produtos. Sendo que, essas questões devem ser dirigidas de acordo com a economia e estratégias de desenvolvimento para a implantação simultânea.

Nas perspectivas de Dobrzanski (2006) a principal prioridade de desenvolvimento da C\&T dos materiais no século 21 está na previsão entre estrutura, processo tecnológico e propriedades funcionais em sistemas complexos de desenvolvimento conjunto entre materiais, tecnologias e produtos direcionados para melhorar as condições de vida da sociedade e do meio ambiente. Com isso, a Tabela 1 apresenta áreas essenciais de desenvolvimento no mundo que devem guiar os avanços na C\&T dos materiais no início deste novo milênio. 
Tabela 1: Direções de desenvolvimento do mundo no século 21 e a C\&T dos materiais.

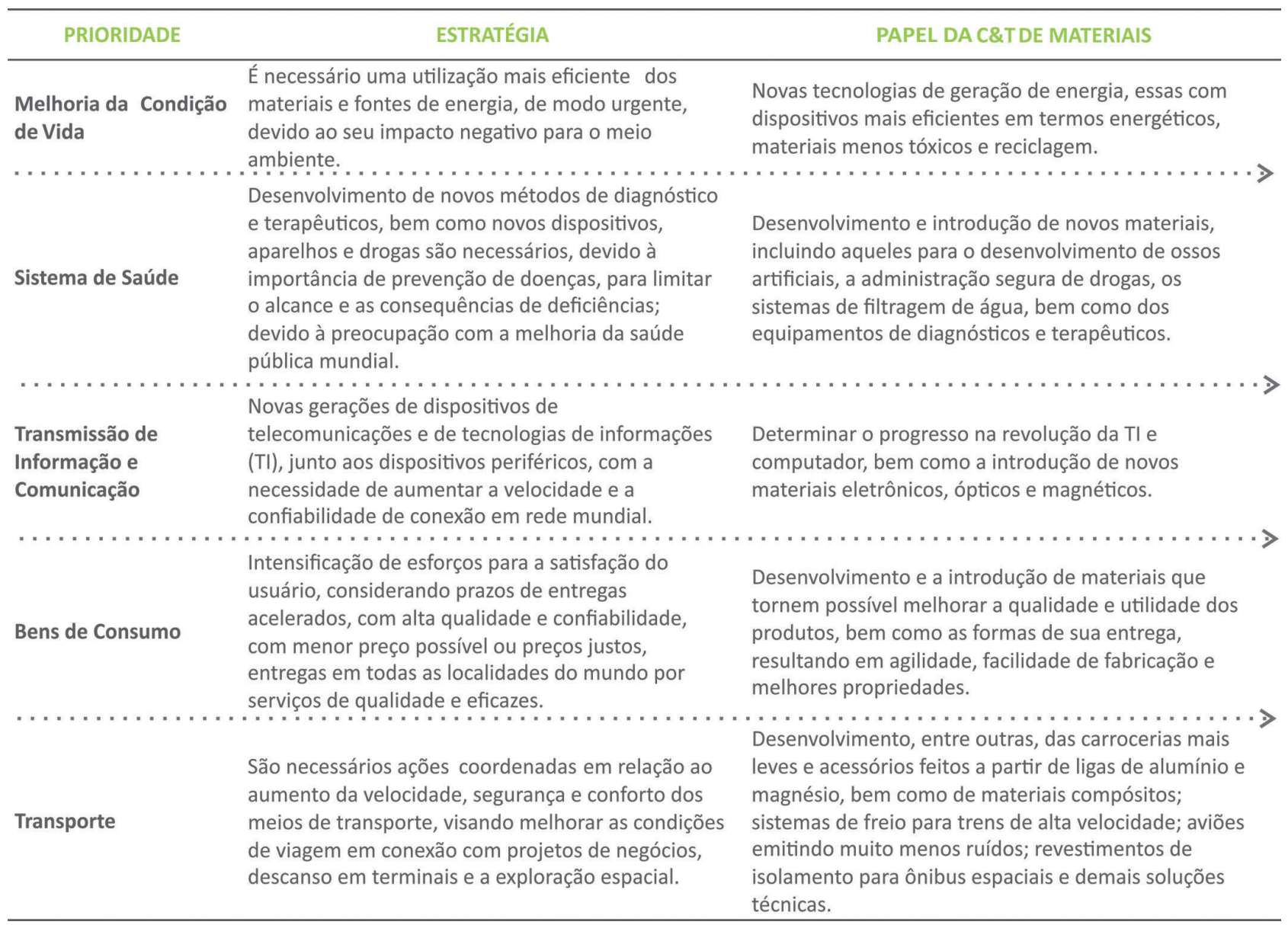

Fonte: Adaptado de Dobrzanski (2006).

Dobrzanski (2006) enfatiza que as atividades estratégicas da C\&T dos materiais no século 21 voltam-se para o design de materiais, a ciência de materiais computacionais, os métodos analíticos avançados, a fabricação e o processamento, as nanotecnologias, os materiais inteligentes e a biomimética.

\author{
No Brasil o Centro de Gestão e Estudos Estratégicos (CGEE) em seu \\ relatório sobre "Materiais Avançados no Brasil 2010-2022" atenta para \\ eixos de propostas que podem "impulsionar a capacidade nacional de \\ atendimento às demandas crescentes de matérias primas e insumos, \\ dentro de padrões de sustentabilidade, competitividade e responsabilidade
}


ambiental e social" (CGEE, 2010, p. 7). O estudo do CGEE reconhece o país como um grande produtor de algumas das principais matérias primas de que depende a humanidade. Com isso, destaca na publicação oito temas como áreas portadoras de futuro para o país, considerando o potencial para o desenvolvimento tecnológico de setores específicos de interesse nacional ou de aplicação global e o aproveitamento ou a agregação de valor aos recursos naturais nacionais. Entre as áreas portadoras de futuro indicadas pelo CGEE está o meio ambiente e os recursos naturais biológicos e minerais. Outras áreas apontadas são: magnéticas, eletrônicas e fotônicas; energia; defesa nacional e segurança pública; atividades espaciais; saúde médico-odontológico e tribologia.

Bell (2011) com uma visão mais ampla e ora convergente com os demais autores, previamente, citados, indica oito tendências mundiais que tem dirigido as novas pesquisas em materiais no século 21, tais como: materiais como moda; segurança; moderno; tecnologia digital; biomimética; nanotecnologia; materiais verdes e materiais inteligentes

Ashby e Johnson (2011) em uma relação próxima ao design com o uso dos recursos materiais apontam para cinco entradas que tendem a influenciar o uso de materiais em um processo de design. Essas entradas são:

a) O clima de investimento para a estratégia do negócio.

b) As necessidades do mercado para a produção.

c) Os conceitos do design diante do usuário para a estética.

d) A preocupação com o meio ambiente para a sustentabilidade.

e) A ciência para os fatores tecnológicos.

Os autores Ashby e Johnson (2011) explicam que novos materiais e tecnologias são exploradas mediante as possibilidades de investimentos. Sendo essas dirigidas por questões econômicas vigentes e atreladas a um mercado de produção e consumo de produtos. A sustentabilidade insere-se nesse contexto atrelada à atual consciência humana por maior qualidade de vida e redução considerável dos impactos negativos gerados ao meio ambiente. Já o design, além de considerar os atributos advindo desses fatores, deve envolver também as questões estéticas e simbólicas em atendimento a um usuário cada vez mais exigente, que 
busca tanto melhores preços e funcionalidade em um produto como satisfação e prazer. Portanto, os avanços científico e tecnológico tornamse cada vez mais essencial para direcionar os investimentos e o mercado, buscar soluções sustentáveis para a sociedade e promover novas experiências significativas ou com significados para as pessoas.

Baykara (2015) acrescenta que no início do século 21 uma nova Era para o design de materiais avançados emergiu influenciada pela dinâmica do mercado e intensa competição. Para o autor os principais desafios no século 21 para a C\&T dos materiais tendem a centrar-se em campos críticos de energia, ambiente, defesa e segurança interna, saúde, transporte, microeletrônica, nanotecnologia, espaço, aviação entre outros que exigem alta desempenho e propriedades melhoradas de materiais avançados. Como campos emergentes o autor cita os biomateriais, os materiais magnéticos, ópticos e inteligentes e os nanomateriais. $\mathrm{Na}$ passagem para o século 21 emergiram da ciência e tecnologia avançada "alta capacidade de modelagem computacional dos átomos e das moléculas para projetar e adaptar novas composições originais e funções sofisticadas" (BAYKARA, 2015, p. 82) em materiais avançados. Isto associado ao rápido avanço das nanociências e nanotecnologias, junto ao desenvolvimento de instrumentos analíticos, altamente, capazes e eficazes para a realização de testes e análises de caracterização de micro e nanoestruturas (por exemplo, microscópios eletrônicos de resolução ultra elevada), conduziram a C\&T dos materiais para uma nova era de relações ao propósito do design de materiais avançados (BAYKARA, 2015).

Por fim, diante das direções de desenvolvimento da sociedade no século 21 entre as áreas de materiais e design, observou-se que muitas das tendências apresentadas traduzem-se em considerações para a sustentabilidade em processos de PD\&I de materiais, tecnologias e produtos. Por exemplo, entre as oito tendências mundiais indicadas por Bell (2011) quatro indicam relação direta com a sustentabilidade, tais como: a nanotecnologia; os materiais verdes, a biomimética e (iv) os materiais inteligentes. Algumas dessas tendências também são citadas por Field, Clark e Ashby (2001); Dobrzanski (2006); Ashby e Johnson (2011) e Baykara (2015). Além da sustentabilidade, as prioridades para o desenvolvimento de materiais e produtos no século 21 consideram a ideia do design de materiais avançados, enfatizada por Dobrzanski (2006) e Baykara (2015). Essas tendências destacadas são discutidas como tópicos a seguir. 


\subsection{Nanomateriais}

Em 1959 o físico Richard Reynman sugeriu que se o movimento de pequenas partes de um material pudesse ser controlado, "seria possivel alterar completamente as propriedades e desempenho das coisas" (BELL, 2011, p. 6). Com isso, na contemporaneidade, as nanociências e nanotecnologias abordam a manipulação da matéria em uma faixa de tamanho de 1 a 100 nanometros (nm) (SAVOLAINEN et al. 2013). A Figura 6 mostra alguns elementos em uma escala nanométrica para esta compreensão.

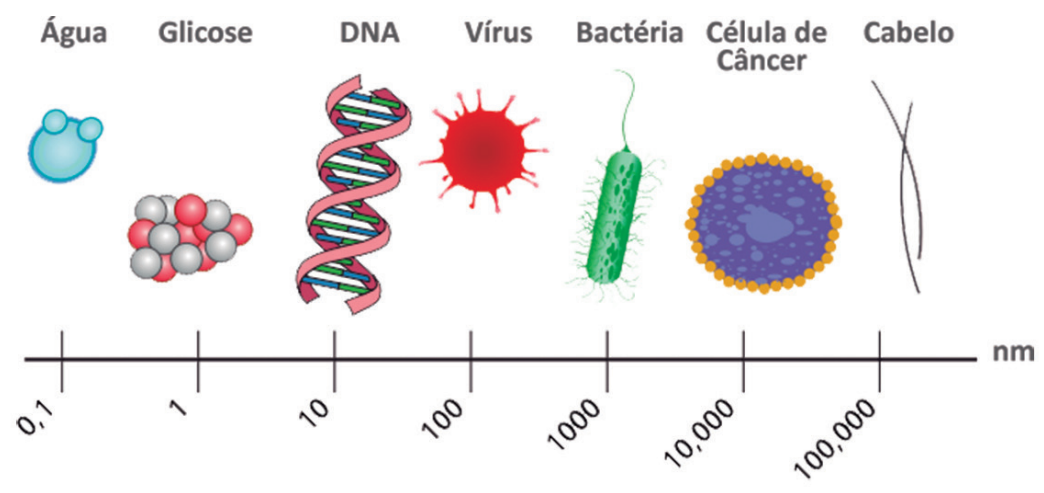

Figura 6: Elementos em uma escala nanométrica. Fonte: Savolainen et al. (2013).

"Nanomateriais inclui todos os materiais nanométricos, desde nanopartículas de engenharia até aquelas que existem na natureza" (BELL, 2011, p. 6). Esses são caracterizados pela sua complexidade diante de propriedades físico-químicas, de comportamento e de interações com sistemas vivos (SAVOLAINEN et al. 2013). Um exemplo de material baseado em nanotecnologia é a nanocelulose, um pseudoplástico produzido por meio de fibras de celulose (BELL, 2011). Khalil et al. (2014) divide as nanoceluloses em três tipos: os nanocristais de celulose, as nanofibrilas de celulose e a nanocelulose bacteriana.

Os nanomateriais "incorporam fisicamente o conceito do século 21 (...), além de ser um novo paradigma material, estão ao mesmo tempo posicionados na interface de muitas disciplinas científicas" (SAVOLAINEN et al. 2013, p. 42), contribuindo para o surgimento de diversos subcampos das nanociências e nanotecnologias como a optoeletrônica, materiais de construção inovadores, novas superfícies, embalagens etc. (ibidem). 
No século 21 os materiais nanotecnológicos tem assumido um papel impar na promoção da inovação, assim como, aqueles oriundos de processos biotecnológicos, também chamados de biomateriais ou materiais verdes.

\subsection{Materiais verdes}

Os materiais verdes são aqueles que utilizam recursos naturais renováveis, processos de produção mais limpa, tecnologias de energia alternativa entre outras estratégias de redução dos efeitos adversos sobre o meio ambiente, tais como os materiais baseados em biotecnologia (BELL, 2011). Neste contexto, um conceito emergente é a Teoria Cradle to Cradle ${ }^{\circledR}$ (C2C), a qual impõe a necessidade de uma economia circular, orientada para o desenvolvimento de toda a cadeia produtiva dos materiais e produtos por meio de dois ciclos, um biológico e outro técnico (BRAUNGART e MCDONOUGH, 2013) (Figura 7).
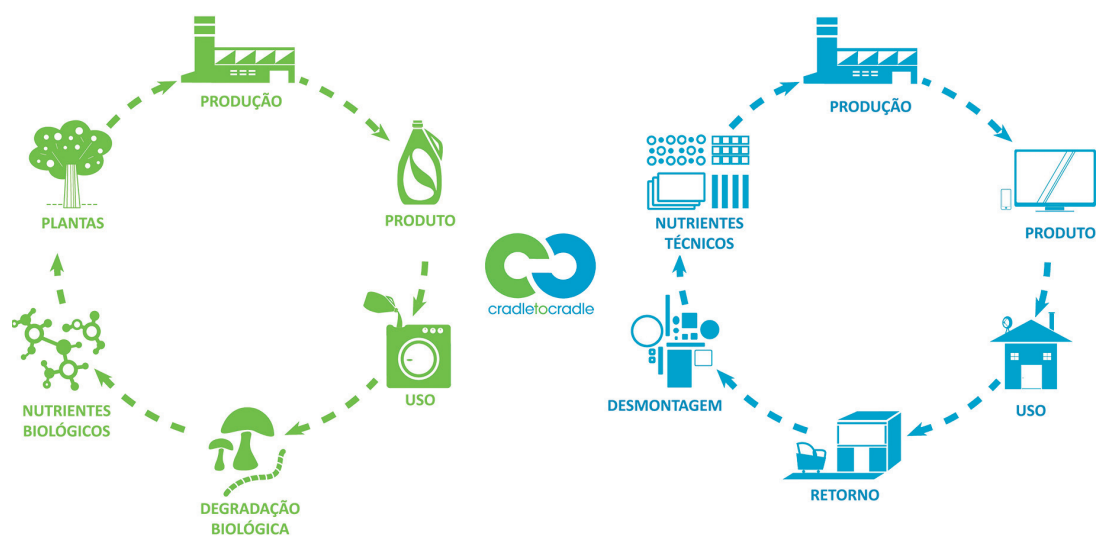

Figura 7: Ciclos biológico e técnico da Teoria Cradle to Cradle ${ }^{\circledR}$. Fonte: Adaptado da C2C Platform (2017).

Nos materiais verdes a tendência vigente é aderir à certificação $C 2 C{ }^{\circledR}$ (BELL,2011) fornecida pelo Programa Cradle to Cradle Product Innovation Institute (C2CPII). Diferentemente de muitos processos de certificação, como a ISO 14001, que confere qualidade ambiental ao processo produtivo, a $C 2{ }^{\circledR}$ visa auditar e creditar o produto com status de alta qualidade para a saúde humana e o meio ambiente (EPEA, 2016). 


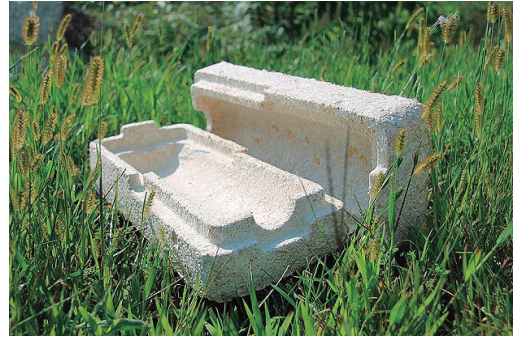

Cradle to Cradle Certified Product Scorecard SAUUDE MATERIAL Platina REUTILIZAÇÃO DO MATERIAL OUR ENERGIA RENOVAVELL GESTÃO DE CARBONO

GESTÃO DAÁGUA

EQUIDADE SOCIAL

NIVELL DE CERTIFICAÇÃO GLOBAL

Figura 8: Material Ecovative Mushroom ${ }^{\circledR}$ e seu scorecard da certificação Cradle to Cradle. Fonte: Cradle to Cradle Certified (2017).

Figura 9: Biocultura e suas aplicações na moda pela designer Suzzane Lee. Fonte: Fairs (2014).
A certificação apresenta cinco critérios de avaliação, tais como: desenho de materiais seguros à saúde; desenho de produtos para reciclabilidade; uso de energias renováveis; gestão da qualidade da água e responsabilidade social (EPEA, 2016). Ainda, essa certificação é composta por uma escala de cinco níveis de avaliação (Basic, Bronze, Silver, Gold e Platinum) a fim de estimular a inovação continuada. O material Ecovative Mushroom ${ }^{\circledR}$ é um exemplo de produto certificado na categoria ouro para quase todos os critérios da C2C ${ }^{\circledR}$ (Figura 8). Esse material usa tecnologia de cogumelos (micélio) para converter resíduos agrícolas (cascas de sementes, talos de milho e rebarbas de algodão) em um material de compostagem. Após um processo de secagem, o Mushroom ${ }^{\circledR}$ pode ser utilizado em diversas formas de aplicação, como na substituição de embalagens de espuma plástica (EPS, EPP e EPE) (CRADLE TO CRADLE CERTIFIED, 2017).

Outro exemplo de material verde é a celulose bacteriana. A designer Suzzane Lee, da Central Saint Martin's College of Art and Design, utiliza celulose biossintetizadas por bactérias para confeccionar peças de roupas e calçados, chamados de biocultura. É um processo de fermentação, no qual ocorre o crescimento bacteriano e a produção do biofilme de celulose (Figura 9).
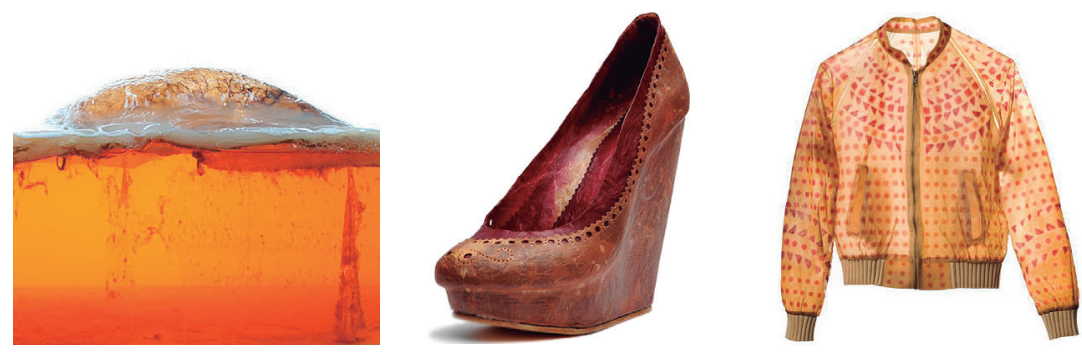

A celulose bacteriana é um material promissor para a promoção da inovação ao oferecer diversas possibilidades de aplicação para muitas áreas produtivas da sociedade, a saber: embalagens ativas em alimentos; têxtil; papel e celulose; biomédica com a engenharia de tecidos (medicina e odontologia); óptica, acústica; cosmética; mineração e refinamento; tratamento de resíduos; purificação de efluentes; ultrafiltração da água etc. (DOMINI et al. 2010). Ainda, pode ser tanto empregada como fonte de combustão quanto usada em combinação com outros materiais ou em substituição a demais materiais, tais como os de origem poliméricas 
(petróleo) e fibrosas (algodão) etc. Classificada como um biopolímero de celulose pura, a celulose bacteriana diferencia-se no cenário atual, sobretudo, pelas suas fibras nanométricas em relação aos micrométricos da celulose vegetal (DOMINI et al. 2010). Tal característica garante tanto alta resistência ao material como elevado potencial para ser usado como biofilme funcionalizado e inteligente. Uma espécie de plataforma por onde é possivel passar alguma informação e gerar respostas a estímulos, como os materiais inteligentes.

\subsection{Materiais inteligentes}

Os materiais inteligentes são aqueles concebidos para serem responsivos a estímulos externos, tais como: stress; temperatura; umidade; $\mathrm{pH}$; elétrico, óptico ou magnético. As suas propriedades podem ser alteradas de forma previsivel ou de modo controlado em resposta ao seu ambiente (BELL, 2011), oferecendo tanto facilidade de uso como contribuições para o meio ambiente.

Um exemplo desta tendência é o projeto Second Skin, desenvolvido por Forro Yao, junto ao Massachusetts Institute of Technology (MIT), com o objetivo de melhorar o desempenho de atletas. A proposta é uma segunda pele baseada em biomateriais e coberta por sensores vivos. São bactérias aplicadas vivas em uma roupa técnica por meio de um sistema de bio-impressão com resolução micro. As bactérias reagem a transpiração com a expansão e abertura de pequenas fendas na roupa técnica. Assim, durante o esforço físico de atletas, o material inteligente será capaz de responder a estímulos de umidade (suor) com a evaporação e, eventual, fechamento dos poros para regulação da temperatura corporal do atleta, melhorando o seu desempenho (Figura 10) (MATERIAL CONNEXION, 2017b).

A proposta Second Skin também traduz como o design pode integrar a biologia em seu processo, movendo-se na direção de conceitos de materiais bioderivados ou bio-híbridos e de materiais inspirados na natureza pelo biomimetismo (MATERIAL CONNEXION, 2017b).
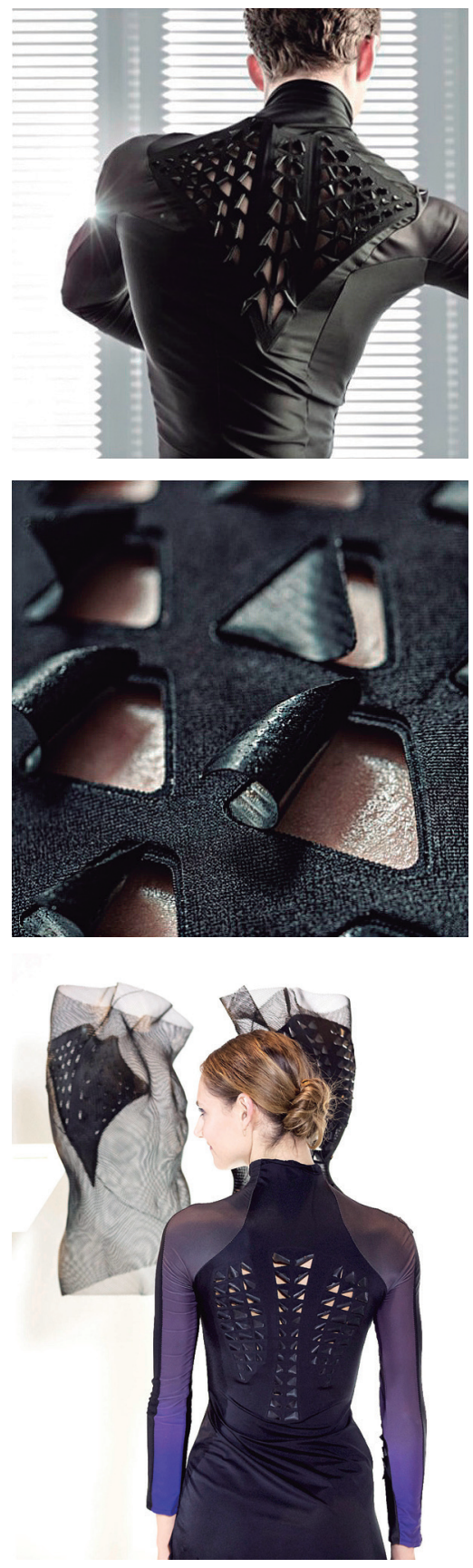

Figura 10. Second Skin de Forro Yao. Fonte: Material ConneXion (2017b). 

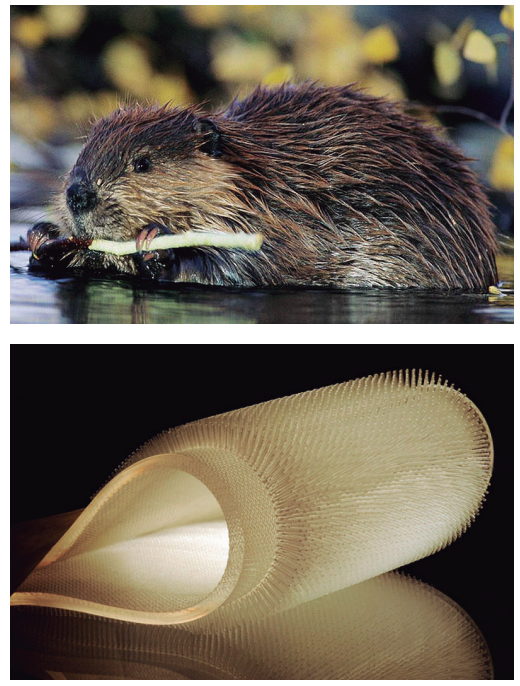

Figura 11: Material Hi Tech para roupas de mergulho com isolamento térmico inspirado na pele de lontras e castores. Fonte: Material ConneXion (2017c).

\subsection{Biomimética}

Na Sociedade Contemporânea há um interesse crescente na concepção e desenvolvimento de novos materiais e produtos inspirados em fenômenos da natureza (BELL, 2011). A biomimética e uma ciência multidisciplinar que estuda a natureza com a finalidade de "aprender com ela e não sobre ela (de bios = vida e mimesis = imitação)" (XXVI PRÊMIO JOVEM CIENTISTA, 2012, p. 78). O objetivo é encontrar inspiração e relações naturais pela observação da estrutura, processos e funções de elementos da natureza a fim de solucionar problemas: "seja qual for o problema do produto a ser desenhado, provavelmente, a natureza já testou e selecionou soluções" (XXVI PRÊMIO JOVEM CIENTISTA, 2012, p. 79).

Pesquisadores do MIT inspiraram-se nas peles de lontras e castores para criar um material avançado que simulam o processo de isolamento da temperatura desses animais. Foi desenvolvido um tecido de borracha com pequenos cones que imitam a pelagem dos animais semi-aquáticos referenciados, oferecendo maior conforto térmico aos usuários de roupas de mergulho, como os surfistas. Os pesquisadores do projeto identificaram que $o$ ar fica preso entre os pelos individuais dos animais quando submersas na água, sendo que o conjunto desses pelos forma uma camada, altamente, eficaz de termorregulação (Figura 11) (MATERIAL CONNEXION, 2017c).

No design aplica-se a biomimética na concepção de produtos novos ou melhorados e na C\&T dos materiais visa-se aprender novos princípios por meio de sistemas biológicos, especialmente, para a criação de dispositivos biomédicos mais compatíveis com o organismo humano. Na contemporaneidade isso é possivel mediante ao advento do design de materiais avançados, que pondera os níveis de complexidade desses sistemas biológicos (OSLON, 2001).

\subsection{Design de materiais avançados}

De modo conexo, campos da C\&T dos materiais e do design voltam-se agora para o contexto e para o valor humano como fatores imprescindiveis para a tomada de decisão nas escolhas ou concepção 
de materiais avançados ao produto. Isto era esperado por Oslon (2001) quando ele ditou a existência da Idade do Design como a Era do pensamento material ou da consciência sobre como criá-lo ou projetá-lo para um novo mundo material. Segundo McBride (2011) neste novo mundo busca-se maior compreensão das consequências ambientais, sociais e econômicas das escolhas de materiais. "Dar às pessoas acesso aos produtos e bens de consumo decidindo, diretamente, sobre o grau de qualidade de vida, o intercâmbio de informação, o nível da qualidade da educação, o potencial dos serviços de saúde e muitos outros aspectos do ambiente em que vivemos" (DOBRZANSKI, 2006, p. 147). Isto expõem o quadro de uma profunda visão humanista na interface entre os materiais e o design.

A intensificação do valor humano e da compreensão dos contextos socioculturais, políticos, econômicos e ambientais propõem a união de múltiplos saberes particulares com a experimentação in loco (contexto). Ainda, tendem a contribuir para o encontro de novos significados em materiais, tecnologias e produtos, o que oportuniza a visualização de novos cenários de PD\&l. Bell (2011) também destacou esta questão como uma tendência quando tratou dos materiais como moda. O material fornece tanto funcionalidade técnica ao produto como personalidade. Por meio dos sentidos (visão, tato, gosto, olfato e audição), da percepção e das emoções atribui-se valor ao material e produto.

A Samsung Chemical SDI, adquirida em 2016 pela LOTTE Advanced Material, foi premiada no iF Design Award 2015 na categoria 'Conceito Profissional' ao evocar a emoção e os sentidos no design de materiais avançados. Foram premiadas três propostas de materiais plásticos ecológicos caracterizados como: Toque e Sensação (promove uma nova experiência ao usuário por três tipos de texturas: crocante, flexivel e nítida); Sentimento Emocional (expressa a textura natural do tecido e da pedra) e Papel com Efeito Plástico (recria a textura mate, a leveza e a imagem suave do papel). São materiais de emoção baseados em tecnologias de processamento que oferecem uma ampla gama de impressões táteis sem processos adicionais de acabamento, como por exemplo, sem pintura (Figura 12) (LOTTE, 2017; IF WORLD DESIGN GUIDE, 2015).

Questões materiais desempenham um papel importante em direção das possibilidades de concepção de novos produtos para a Sociedade
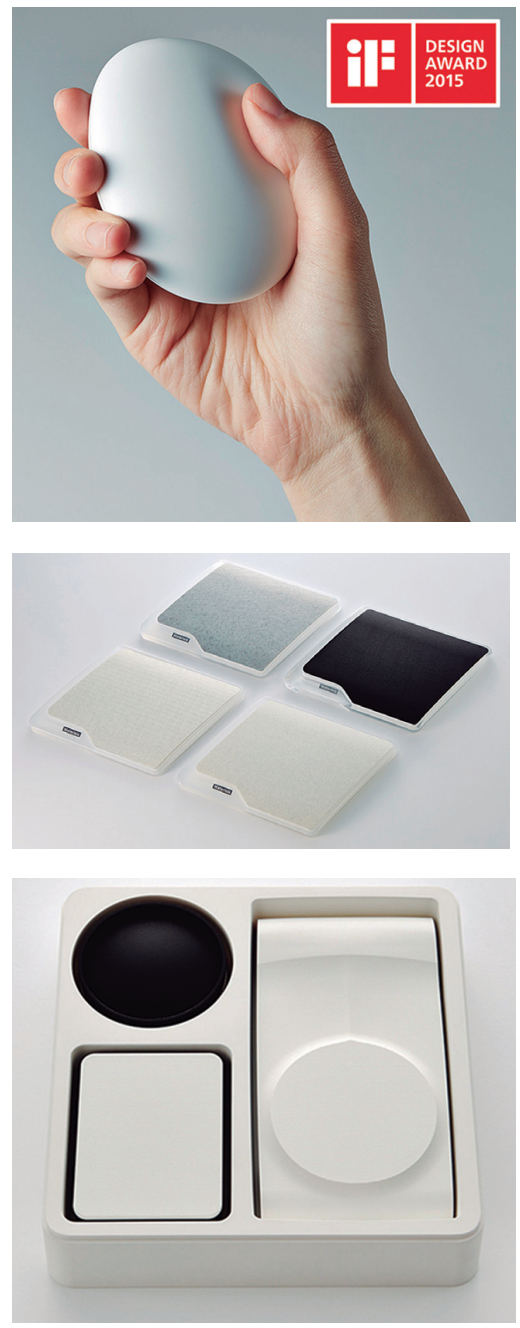

Figura 12: Materiais avançados da Samsung Chemical SDI premiados no iF Design Award 2015. Fonte: If World Design Guide (2015). 
Contemporânea. Contudo, apesar das direções de desenvolvimento no século 21 destacarem uma relação mais próxima entre as áreas da C\&T dos materiais e do design, segundo Ashby e Johnson (2011) o que se observa ainda é uma lacuna na comunicação entre designers e desenvolvedores de materiais. Para os autores futuros avanços nesta relação dependerão fortemente da colaboração mútua entre as áreas. Baykara (2015) corrobora essa visão ao afirmar que a inovação, criatividade e extensa colaboração em PD\&l estão se tornando os principais pilares para quase todas as organizações. Entretanto, o autor pondera que apesar de novas conquistas técnicas e científicas surgirem regularmente, ainda há uma falta de pesquisa em tecnologia e gestão da inovação de materiais avançados, considerando suas características diversas e multisetoriais, tais como: inovação e criatividade; colaboração em rede; desempenho crítico e multifunções especiais.

Por fim, com a tendência para a gestão do conhecimento indicada por Field, Clark e Ashby (2001) e para o design de materiais avançados da C\&T dos materiais apontada por Dobrzanski (2006) e Baykara (2015), junto à teoria e prática do design, ressaltada, principalmente, por Oslon (2001); Field, Clark e Ashby (2001) e Ashby e Johnson (2011) têm-se uma combinação de áreas potenciais para a criação de projetos de gestão de PD\&l em materiais, tecnologias e produtos no século 21.

\section{CONCLUSÃO}

Conclui-se compreendendo que a formulação dos materiais avançados oportunizou a inserção da estratégia PD\&I na concepção simultânea de novos materiais, tecnologias e produtos. Tal concepção foi chamada de design de materiais e dirigida por várias tendências para a inovação e para o desenvolvimento da sociedade no século 21. Muitas dessas tendências traduzem-se na consideração da sustentabilidade em processos de PD\&l, tais como os nanomateriais, os materiais verdes, os materiais inteligentes e a biomimética. Os materiais como moda também são realçados pela recente visão humanista instaurada nas ciências e práticas, destacando a criatividade e a colaboração como demandas emergentes. 
Assim, as tendências para o desenvolvimento da sociedade no século 21 , em relação a interface entre os materiais e o design, cada vez mais, aproximam-se das ciências naturais. Isto, tendem a influir no design de materiais avançados, direcionando-os para a aplicação em produtos de modo mais significativo para as pessoas e para o meio ambiente, por meio da consideração de valores tangiveis e intangiveis. Com esta perspectiva abre-se um campo amplo de oportunidades de estudos em PD\&I, tais como: sobre as experiências materiais para as pessoas, relacionadas à tendência de materiais como moda; sobre as reais demandas para a sociedade e seus problemas complexos (wicked problems) e sobre a criação de inovações sustentáveis, como aquelas introduzidas pela teoria Cradle to Cradle.

As soluções sustentáveis são uma demanda vigente na Sociedade Contemporânea, o que exige da C\&T dos materiais e do design considerar esta questão intrínseca aos seus processos e direcionar seus questionamentos para as reais demandas da sociedade. Concorda-se com McBride (2011) quando a autora afirma que os designers devem ajudar as pessoas a reconhecerem e respeitarem os limites entre o raro e real, fazendo alusão aos materiais críticos e às demandas por desejos. Ao buscar a inovação no século 21, a concepção de materiais e design deve estar, necessariamente e intuitivamente, conectada a uma consciência material, sobre como projetar e criar para um novo mundo material.

\section{REFERÊNCIAS}

ASHBY, M.; JOHNSON, K. Materiais e design: arte e ciência da seleção de materiais no design de produto. 2. ed. Rio de Janeiro: Elsevier, 2011.

BAYKARA, T. From the classical scheme to a smart/functional materials system: A generic transformation of advanced materials technologies. In: $3^{\text {rd }}$ International Conference on Leadership, Technology and Innovation Management. Procedia - Social and Behavioral Sciences, n. 181, p. 79-88, 2015.

BELL, B. Material intelligence: an overview of new materials for manufacturers. PFInnovation, Canadá, 2011.

BRAUNGART, M.; MCDONOUGH W. Cradle to gradle: criar e reciclar ilimitadamente. São Paulo: G. Gili, 2013.

CGEE. Materiais avançados no brasil 2010-2022. Brasilia: Centro de Gestão e Estudos Estratégicos, 2010 
CRADLE TO CRADLE CERTIFIED. Ecovative Mushroom ${ }^{\circledR}$ Material. Disponível em: <http://www. c2ccertified.org/products/scorecard/mushroom_material>. Acesso em: set. 2017.

C2C PLATFORM. Cradle to Crade. Disponível em: <http://www.c2cplatform.tw/en/c2c. php?Key=1>. Acesso em: set. 2017.

DOBRZANSKI, L. A. Significance of Materials Science for the Future Development of Societies. Journal of Materials Processing Technology, n. 175, p. 133-148, 2006.

DONINI, I.; DE SALVI, D.; FUKUMOTO, F.; LUSTRI, W.; BARUD, H.; MARCHETTO, R.; MESSADDEQ, Y.; RIBEIRO, S. Biossíntese e recentes avanços na produção de celulose bacteriana. Eclética Química, v. 35, n. 4, 2010.

ENERGY. Top 10 things you didn't know critical materials. Disponivel em: <http://energy.gov/ articles/top10thingsyoudidntknowaboutcriticalmaterials>. Acesso em: jan. 2016.

EPEA. Cradle to Cradle. Disponivel em: <http://epea-hamburg.org/en/content/cradle-cradlecertifiedtm-certification>. Acesso em: jan. 2016.

EUROPEAN COMMISSION. Report on critical raw materials for the EU: Report of the Ad hoc Working Group on defining critical raw materials. May 2014. Disponivel em: <http://www. catalysiscluster.eu/wp/wp-content/uploads/2015/05/2014_Critical-raw-materials-for-theEU-2014.pdf>. Acesso em: jan. 2016.

FAIRS, M. Microbes are "the factories of the future". In: Dezeen and MINI Frontiers, 2014 Disponivel em: <https://www.dezeen.com/2014/02/12/movie-biocouture-microbes-clothingwearable-.futures/>. Acesso em: set. 2017.

FIELD, F. R, CLARK, J. P, ASHBY, M. F. Market Drivers for Materials and process development in the 21st century. MRS BULLETIN. 2001.

FUCK, M.p. VILHA, A. M. Inovação tecnológica: da definição à ação, Dossiê C,T\&l: dilemas sociais na Contemporâneos: Revista de Artes e Humanidades, v. 2 (online), abr. 2011.

GERHARDT, E.; SILVEIRA, D. T. Métodos de pesquisa. Universidade Aberta do Brasil - UAB/ UFRGS, Curso de Graduação Tecnológica - Planejamento e Gestão para o Desenvolvimento Rural da SEAD/UFRGS - Porto Alegre: UFRGS, 2009.

GLOBAL FOOTPRINT NETWORK. Ecological footprint. Disponivel em: <http://wwW. footprintnetwork.org/our-work/ecological-footprint/>. Acesso em: ago. 2017.

IF WORLD DESIGN GUIDE. Samsung SDI: Awards. In: if Design Award 2015. Disponivel em: <http://ifworlddesignguide.com/profile/2028-samsung-sdi> Acesso em: set. 2017.

KHALIL, H.p. S. A.; DAVOUDPOUR, Y.; ISLAM, N.; MUSTAPHA, A.; SUDESH, K.; DUNGANI, R.; JAWAID, M. Production and modification of nanofibrillated cellulose using various mechanical processes: a Review Carbohydrate Polymers, v. 99, p. 649-665, 2014.

KULA, D.; TERNAUX, E. Materiologia: o guia criativo de materiais e tecnologias. São Paulo: Senac, 2012.

LAGI, Land Art Generator. Ring Garden. In: LAGI 2016, Santa Mônica - Califórnia, 2016. Disponivel em: <http://www.landartgenerator.org/project.html>. Acesso em: ago. 2017.

LOTTE, Advanced Materials. Awards: LOTTE Advanced Materials. Disponivel em: <https://www. lotteadms.com/jsp/eng/pr_center/sm_awards.jsp>. Acesso em: set. 2017.

MATERIAL CONNEXION. La library. Disponível em: <http://it.materialconnexion.com/ iscriviti/la-library/>. Acesso em: set. 2017a. 
MATERIAL CONNEXION. Lining Yao presenta a Milano "Second Skin", il tessuto iper-traspirante sviluppato dal MIT. Disponivel em: <http://it.materialconnexion.com/lining-yao-presentamilano-second-skin-tessuto-iper-traspirante-sviluppato-dal-mit/>. Acesso em: set. 2017b.

MATERIAL CONNEXION. Nuovo materiale ispirato al pelo dei castori. Disponivel em: <Fonte: http:// it.materialconnexion.com/materiale-ispirato-al-pelo-dei-castori/>. Acesso em: set. 2017c.

MATERIAIS 2015, Simpósio Internacional de Materiais. Palestrante convidado, Margarethe Hofmann-Amtenbrink Critical materials in smart products: Chances and Challenges for Materials Science and Engineering. Disponível em: <https://paginas.fe.up. pt/ materiais2015/wd/ conference/invited-speakers/>. Acesso em jun. 2015.

MCBRIDE, M. Catalyst: Strategic Design Review. n. 7, 2011

OSLON, G. B. Beyond Discovery: Design for a New Material World. Calphad, v. 25, n. 2, p. 175190, 2001.

PADILHA, A. F. Materiais de engenharia: microestrutura e propriedades. São Paulo: Hemus, 2000.

ROTHER, E. T. Revisão sistemática X revisão narrativa. Acta paul. Enferm. (online). v. 20, n. 2, p. V-VI, 2007.

SAVOLAINEN; K, BACKMAN; U, BROUWER; D, FADEEL; B, FERNANDES; T, KUHLBUSCH; T.; PYLKKÄNEN, L. Nanosafety in Europe 2015-2025: towards safe and sustainable nanomaterials and nanotechnology innovations. Finnish Institute of Occupational Health, Helsinki, 2013.

UNITED NATIONS, Department of Economic and Social Affairs, Population Division. World Population Prospects: The 2015 Revision, Key Findings and Advance Tables. Working Paper n. ESA/P/WP. 241. New York. 2015.

VOSGERAU, D. S. A. R.; ROMANOWSKI, J.p. Estudos de revisão: implicações conceituais e metodológicas. Rev. Diálogo Educ, Curitiba, v. 14, n. 41, p. 165-189, jan./abr. 2014.

XXVI PRÊMIO JOVEM CIENTISTA. Aplicação e desenvolvimento de materiais esportivos. In: Kit Pedagógico. Caderno de Conteúdo, 2012. Disponível em: <http://estatico.cnpq.br/portal/ premios/2013/pjc/imagens/publicacoes/07_KitXXVIPJC_CadernoConteudo_Cap3.pdf>. Acesso em: jul. 2014. 
